\title{
Editorial: The Economics of Protected Marine Species: Concepts in Research and Management
}

\author{
Kristy Wallmo ${ }^{1 *}$, Kathryn D. Bisack ${ }^{2}$, Daniel K. Lew ${ }^{3}$ and Dale E. Squires ${ }^{4}$ \\ ${ }^{1}$ Headquarters, NOAA Fisheries, Silver Spring, MD, USA, ${ }^{2}$ Northeast Fisheries Science Center, NOAA Fisheries, Woods \\ Hole, MA, USA, ${ }^{3}$ Alaska Fisheries Science Center, NOAA Fisheries, Seattle, WA, USA, ${ }^{4}$ Southwest Fisheries Science Center, \\ NOAA Fisheries, La Jolla, CA, USA
}

Keywords: valuation, noncompliance, incentive instruments, ecosystem services, protected species

The Editorial on the Research Topic

The Economics of Protected Marine Species: Concepts in Research and Management

\section{OPEN ACCESS}

Edited by:

Stuart Bruce Kaye,

University of Wollongong, Australia

Reviewed by:

Antonios D. Mazaris,

Aristotle University of Thessaloniki,

Greece

*Correspondence: Kristy Wallmo

kristy.wallmo@noaa.gov

Specialty section:

This article was submitted to Marine Affairs and Policy,

a section of the journal

Frontiers in Marine Science

Received: 07 July 2016 Accepted: 08 September 2016 Published: 23 September 2016

Citation:

Wallmo K, Bisack KD, Lew DK and Squires DE (2016) Editorial: The Economics of Protected Marine

Species: Concepts in Research and Management. Front. Mar. Sci. 3:183.

doi: 10.3389/fmars.2016.00183
Protected marine species have populations that are depleted, decreasing, or are at-risk of extinction or local extirpation. As of 2015, the International Union for the Conservation of Nature, a global environmental organization, listed approximately 737 marine species worldwide that are considered endangered and vulnerable to extinction, noting that to date only a fraction of the world's marine species have been assessed. Many of these species are provided legal protection through national laws that require research and management measures aimed at recovering and maintaining the species at a sustainable population level. In the U.S. for example, the Endangered Species Act and the Marine Mammal Protection Act provide protection for 143 marine species. Integral to the policy decision process involving the management and recovery of marine species is the consideration of the economic and ecological costs and benefits of protection. This suggests that economics, at its core the study of tradeoffs, has a significant role. First, economics provides a decision theoretic framework for considering all benefits and costs to society associated with policies and management actions aimed at protecting species. In addition, economics contributes to the development of incentive-based management tools (such as property rights-based policy instruments) and can provide a framework for evaluating them against more traditional command-and-control tools (such as closures). The articles in this Research Topic identify various contributions that economics can make to protected species research and management.

In the opening article Lent outlines key reasons marine resource managers should consider economics in protected species research and management and focuses on two specific contributions: economic valuation and market-based management tools. Economic valuation tools provide a way to measure the benefits of things such as protecting marine species, their habitat, and the services they provide. This enables them to be formally included in regulatory analyses, environmental mitigation cases, and marine management approaches in which the evaluation of trade-offs is inherent. Market-based management tools such as catch share programs, permit buy-backs, conservation leasing, etc., address fundamental drivers of human behavior and provide flexibility and incentives for innovation which traditional tools (e.g., command and control) often lack. Such incentives often lead to maintaining profitability while producing desired protected species management results.

The next set of articles in the Research Topic explores economic valuation. The articles begin with Lew, who provides a comprehensive literature review of marine species valuation estimates 
and discusses their potential use in management and policy. This is followed by Wallmo and Lew who present an empirical application valuing the recovery of eight threatened and endangered marine species in the U.S. and examine the effect of the sampling scope and scale on benefit measures. Forbes et al. provides another example of an empirical application valuing alternative management actions for recovering a representative species of Pacific rockfish. Weber estimates the benefits of recovering salmon species in the Pacific Northwest and illustrates some of the challenges with the use of secondary data in economic valuation. Cole and Moksnes use a production function approach to quantify links between three eelgrass functions (habitat for fish, carbon, and nitrogen uptake) and economic goods in Sweden, thus relating ecosystem services such as commercial fisheries, carbon, and nitrogen sequestration (outputs) to marine habitat (inputs) to estimate the value of protecting marine habitat. Finally, Cardenas and Lew investigate issues related to funding conservation programs for endangered species. They provide insights into factors affecting tourists' willingness to contribute monetarily toward the conservation of two marine protected species, green sea turtles and hammerhead sharks.

The following set of articles begin with Innes et al., who review the literature on market-based management tools used to promote conservation while reducing negative impacts associated with commercial fishing. In Bisack and Das noncompliance issues with management and regulations are explored. They examine economic and normative (e.g., moral, social, legitimacy) factors that may affect compliance behavior by developing and estimating an empirical model to explain a fisherman's compliance decision with respect to marine mammal regulations. The final article on management tools by Bisack and Magnusson discusses the need for ex-post analyses of policy instruments used to conserve protected marine species. They assess policy instruments' expected efficacy with respect to multiple criteria, including biological, economic, socio-normative, and longevity objectives. The Research Topic concludes with an article by Speir et al. who use dynamic optimization techniques to determine the optimal timing for dam removal in a large-scale restoration project involving endangered salmon. The study compliments the focus areas of the other articles by underscoring the importance of addressing uncertainty when modeling economic and ecological costs.

The collection of articles in the Research Topic illustrates important concepts, gaps, and challenges in protected species economics, serving as a first step toward improving our knowledge base and raising critical dimensions for future research. Efforts such as this can facilitate collaboration among scientists and even across disciplines, offering a valuable tool to enhance protected species research and management.

\section{AUTHOR CONTRIBUTIONS}

All authors listed have made substantial, direct and intellectual contribution to the work, and approved it for publication.

Conflict of Interest Statement: The authors declare that the research was conducted in the absence of any commercial or financial relationships that could be construed as a potential conflict of interest.

Copyright (c) 2016 Wallmo, Bisack, Lew and Squires. This is an open-access article distributed under the terms of the Creative Commons Attribution License (CC BY). The use, distribution or reproduction in other forums is permitted, provided the original author(s) or licensor are credited and that the original publication in this journal is cited, in accordance with accepted academic practice. No use, distribution or reproduction is permitted which does not comply with these terms. 